\title{
Internal and External e-Customs Services IOS Application Case Study: Kuwait Customs Department
}

\author{
Soha Aljaber ${ }^{1} *$, Nayfah Mohsen Almutairi ${ }^{2}$, Abdulrahman Alkandari ${ }^{3}$ \\ ${ }^{1}$ Computer Department, Secretary Institute (PAAET), Kuwait \\ ${ }^{2}$ Islamic Studies Department, Ministry of Awqaf and Islamic Affairs, Kuwait \\ ${ }^{3}$ Computer department basic education collage (PAAET), Kuwait
}

\begin{tabular}{l} 
Article Info \\
\hline Article history: \\
Received Jan 9, 2018 \\
Revised Mar 2, 2018 \\
Accepted Mar 18, 2018 \\
\hline Keywords: \\
Custom e-government \\
e-Customs services \\
Global position system \\
iPhone operating system \\
Smartphones
\end{tabular}

\begin{abstract}
Government regulations usually characterized by the many stages of completion of any transaction and that causing a delay in the work and that wasting a lot of time. Especially with the particular customs system which consists of several points of entry, including land, sea, and air. In addition, the General Customs Department is one of the sensitive circuits in the state. Therefore, to continue the process any shipment or any transaction relating to customs, it requires a long time. This paper presented a design for an application that running on smartphones with IOS system. This application provides internal services and external services for the General Customs Department to ease the completion of any transaction either for the customs' employee or the citizens. The employee uses the internal services section, and the external services section is used by the citizens. As a result of this application, it provides time and effort for the citizens and customs and decreasing the number of customs' reviewers.
\end{abstract}

Copyright @ 2018 Institute of Advanced Engineering and Science. All rights reserved.

\section{Corresponding Author:}

Soha Aljaber,

Computer Department

Secretary Institute (PAAET), Kuwait

Email: sj.aljaber@paaet.edu.kw

\section{INTRODUCTION}

Government agencies and public sector institutions began in some developed and developing countries. The adoption of e-business concepts; to accomplish their activities and their everyday work, and to provide services to citizens, has crystallized the concept when these organs and institutions providing allowed those services through electronic means (internet, phone...) for individuals and government departments as well as the private sector. The index of the rapid developments in information technology, a profound impact on the way it works, and people communicate in various parts of the world, which requires the development of methods of interaction between citizens and local government [1].

E-government is a new style and sophisticated management through which to raise labor and administrative efficiency level and to improve the business environment to make easy the services provided by private and state-owned commercial companies to the level of the beneficiary under this new style of citizens. Residents and workers can accomplish all transactions and get things done that relate to government Macs and even obtain official papers through electronic means such as the Internet and smartphones and high efficiency quickly. Arab countries have entered the world of economic transformation of the electronic government, globalization and aggressively to meet the challenges and overcome the difficulties that may exceed the allowable limit. A new format, a new addition to modern state and benefits as much as possible of the development of electronics and software in information and communications systems. Devotes a digital map in the world, where many Arab cities-such as Dubai, Muscat, Oman, Kuwait, Cairo, Jordan ... and others - began work on the adoption of new projects to develop and raise the e-government, because its features numerous positive and Services, and began to be carried out gradually and applied. It has already begun to 
provide new services and essential information through electronic means of communication and the Internet. These experiences have made a quantum leap in the level of the Arab cities in the ranks to become the major cities in the world [2].

Developed technology entered walks of modern life mouth technological acceleration witnessed in days. It is incumbent on individuals and governments around the world that matched until life becomes intelligent and more efficiently with the acceleration of technological world growth and connect it to this efficiency and possibilities. The institution that recognizes this potential and usefulness can benefit information network Available in a way were not available by instant communication. Communications with customers allow the institution to enter the market first, and access to the client quickly. In addition, the applications where the amazing features available and enhance the ease of access to information and to be easy and elegant that lead to attracting the attention of users.

Even the most sophisticated applications relating to the institution will ensure new products or the use of tablet PCs or mobile "smartphones" applications used by users inside or outside the organization, which is changed the technical, and informatics arena forever because of mobile devices, computing and tablet computers and devices that rely on touch "smartphones". This change is motivated by flexibility and the ability of those devices and features; it has also changed the way people work and the way they communicate and search for information and share it. It is estimated that more people are now using mobile devices to access the Internet instead of using the surface traditional desktop computer. With the continuation of this trend and multiply the number of users of mobile phones, the manufacturers of mobile phones and communication devices worked tirelessly and tried to move forward for the advancement of technical and functional advantages and flexibility of their products and services.

Therefore, this paper presented a design for an application that running on smartphones with IOS system. This application provides internal services and external services for the General Customs Department to ease the completion of any transaction either for the customs' employee or for the citizens. The employee uses the internal services section to gain the benefits of this application such the registration of companies, reconnaissance suspicion reports, complaints, maintenance requests and Logout option. Also, the external services section is used by the citizens which provide the citizens with several services such: registration of companies in the customs system, suspicion report of contraband, the complaints, required document, location, and contact. This application saves time and effort for the citizens and customs and decreasing the number of customs' reviewers.

\section{PROBLEM STATEMENT}

At this present time, there is a mixed-use in PES Customs Kuwaiti system, but the current system suffers from a weakness in some of the things that will lead to a delay of work and effort and wasting time. The most problem that faced users and reviewers is the large numbers of imports and exports on the border of the State of Kuwait ports and the mismatch of the Wild ports that will connect Kuwait in deserts with the border. For example, Nuwaisib port or Salmi port in Saudi Arabia and Kuwait, it is commercially connected to a press vehicle laden with goods and commodities waiting for a day in the border area are allowed to wait for several days and the customs for clearance and adding tariffs on goods imported into Kuwait.

Customs trade the transactions that pass by tanker trucks and time-consuming in addition it recommends that it be sealed in a paper and it would be up to the main Administration of Customs shall take the things done but in a long routine.

There are many internal things for the Customs Service requirement development and work to improve performance and add some features, which facilitate the service process to the public and staff. However, the problem that faced by the department is that the inner workings with slow orders. The internal other sections inside the circle mismatch IT department or computer hardware maintenance department, are currently inside the circle, but it should make a phone call to the concerned section for any maintenance operation of networks or computer hardware or software installed on the staff and equipment, while the response from the department concerned. This takes a long time and leads to a waste of time and effort and work.

Moreover, other problems that confront daily inside the circle in dealing with auditors and wanted to know the conditions of goods that affect them in the Kuwaiti customs department stores do not forget that the State of Kuwait contains several ports (ground, air, and sea), all of which lead to the customs office. Eventually, the pressed-daily work generates a desire to devise a new mechanism to resolve some of the daily routine problems that can be solved electronically by contributing to the load distribution that declared the shoulders of the employee in the department [3]. 


\section{RELATED PROJECTS}

In 2006, Boujarwah mentioned in his paper that: the e-government provides official electronic Kuwait Portal services to all sectors of the Kuwaiti society of citizens and residents and official bodies and the private sector and visitors. Portal is a gateway to information and data and government services non-stop for seven days a week and 24 hours, and the services are in Arabic and English. Where the gate allows visitors to recognize a lot of information and services, systems and laws relating to the State of Kuwait through multiple access channels such as the Web or various means of communications technology. [4]

Al-shames presented a paper in 2011 defined the Saudi Gateway as the National E-Government and port Unified e-Government services in the Kingdom of Saudi Arabia. It is supervised by the program, and managed by a professional team is keen to apply the highest technical standards for electronic gates as permanently seeks to apply new technologies that contribute to the enrichment of the gate and facilitates access to all its contents, which leads to an increase in the number of users and visitors to the gate and raise the extent of their interaction. [5]

Dr. Ahmad Hamad Al Mahanadi in his paper explained that the E-Government in the State of Qatar aims to provide a better life for the community; where the use of technology in the world seeks to provide simpler and faster solutions. In addition, the advancement of technology to government bodies with new opportunities to connect with the public and the business world to meet their needs, as well as providing the tools needed by government officials to provide world-class effective and outstanding service innovation. The State of Qatar will work to adapt the technology to realize the real value of e-government and to meet the needs of all clients. [6]

Ifram Jami presented a paper, which discussed the Jordanian e-government Authority that performs a many of the tasks starting from the proposal and appropriate legislation and present the public policy programs Jordanian e-government to the Supreme Committee for approval. That leading to the implementation of government transformation programs aimed at the development of government work, which has been approved by the Commission, including improved systems and frameworks in place, standards, and policies. In addition, it required IT programs, facilitating integration, communications, and services between all government agencies, the establishment of electronic channels for the delivery of government services, provide technical and cognitive support to the various ministries and government agencies, as well as organizing awareness and marketing campaigns for the e-government program locally and internationally. [7]

Hassan Tawah discussed in his paper that: Dubai is continuously working to improve the transparency of the business and the development of dynamic systems help consumers and contribute to the formation of small and medium enterprises. Economic Development and Dubai Customs have worked exceptionally to anticipate the time in the area, where headed towards a more streamlined system for electronic services through online applications and smartphones [8].

Heilig and $\mathrm{VoB}$ categorized and overview the importance of information technology in enhancing the performance of ports and how to eliminate the gap between industrial solutions and academic works [9].

$\mathrm{Al}-\mathrm{Sai}$ and Abualigah investigated the concepts of the big data and how its implementation influences the e-governments in enhancing the services delivered. They proposed a solution to overcome such influences [10].

\section{IMPLEMENTATION}

The interfaces are divided in this application on only a specific category of users. The first group is the General Customs staff. The other category is the ordinary citizens and users of the application. Since each of them has an interface with its own services and the introduction of its own, the internal user must log in with a username and password to take advantage of the application.

This section explains the application as mentioned previously; it is divided into two categories they are employees and citizens. Staffs are in the internal section of the application services and citizens in the external services department and will be explained in sections each of them separately.

In the internal services: The Staff user should login with username and password. Then, the application will ensure the login process if it completes successfully or not. If there is an error in the login process, the application will send the user an "Error" Message. Moreover, if the process is complete successfully, the user can use the services of the application. In the External services: the citizen's user can use their own services of the application.

As shown in Figure 1, it shows the mechanism of the flow of data in the application as a whole. In this section, as shown in Figure 2 is dedicated to the citizen's segment divided this section into six main sections: registration of companies in the customs system, suspicion report of contraband, the complaints, required document, location, and contact. Figure 2 focuses on the first three sections: registration of 
companies, suspicion report of contraband and the complaints. In these sections, it is required to fill out the required fields entirely, in the event that the citizen has sent an application for registration of a company or report suspicion or complaints. If the required fields are not complete, the application will give the user notice that the filling in the blanks forgotten. In the case that he has sent the request successfully, the application will give a thank message to the user. Then, data will be sent directly to the base data to be handled by specialists in Customs.

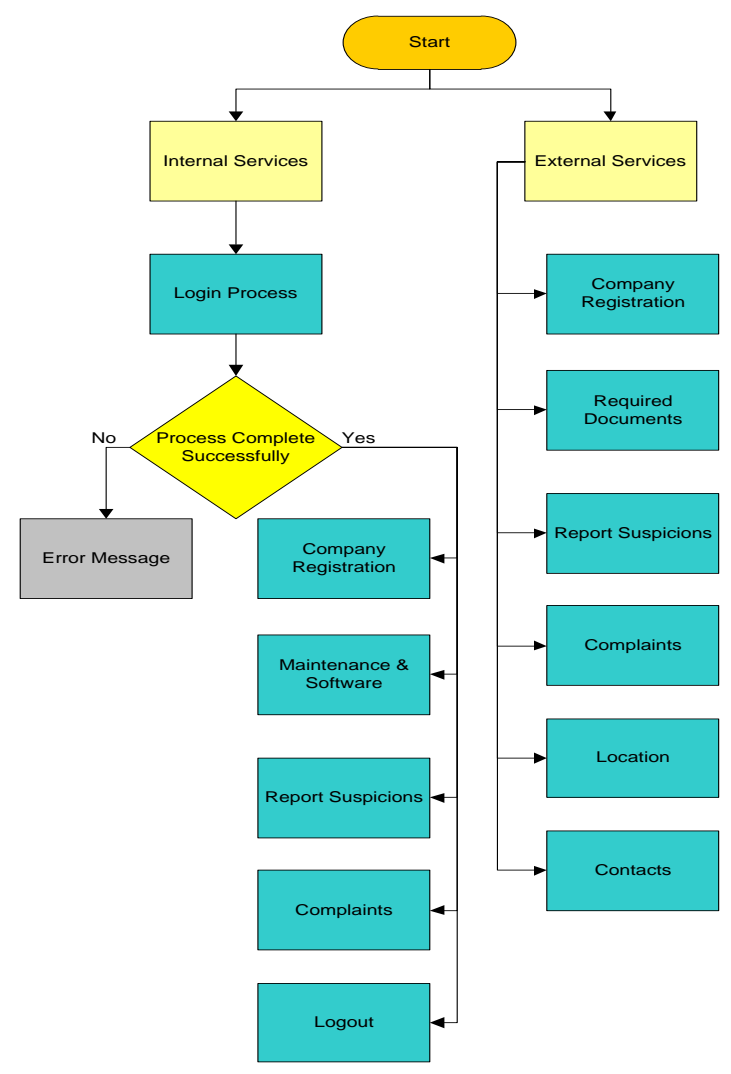

Figure 1. General administration of the application

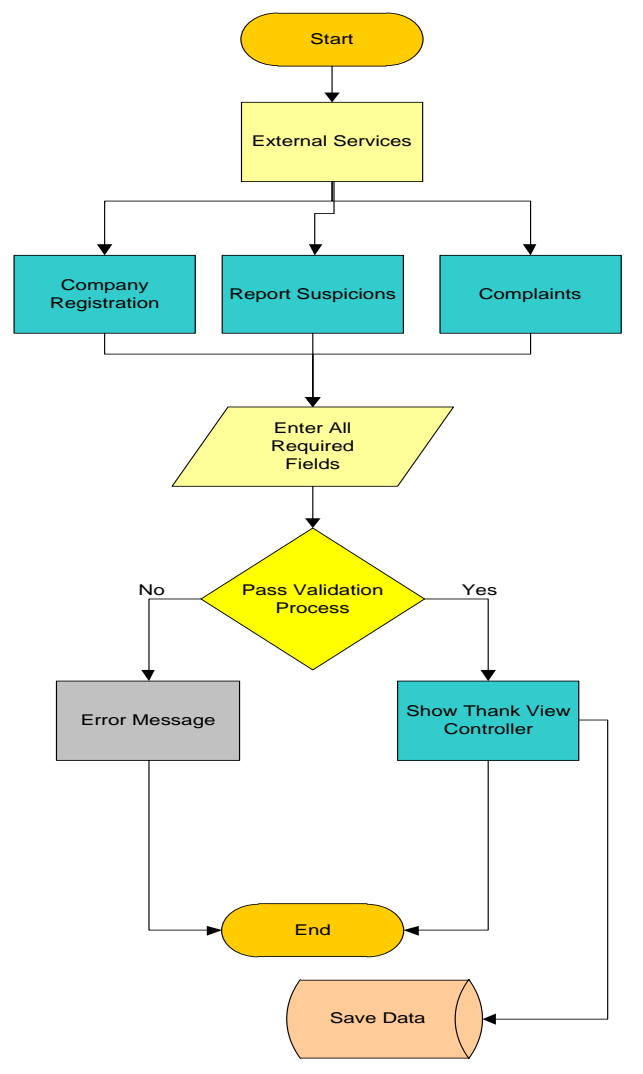

Figure 1. Custom external services

In this section, Figure 3 explained the second three sections on the external services clearly. The required documents, which is the necessary paperwork department to make any services specializes in general department of customs. Then, the location section shows the locations and places that belong to the circle where the user can navigate to the list located in customs areas. In addition to identifying its location through GPS, while the final section is the contacts section that belongs to the General Customs Department.

Figure 4 shows the common part for Employees special customs and this section for automatic access to the application where the grant each user a unique username and password. To prevent the repeat of usernames in the application, it will use the Kuwaiti Civil figure where that there is no similarity or repetition in this figure.

There will be a mechanism entry of free entry for username and password in the application of who shall verify the data entered if they are already existing. In the case that it existed it can have access to the application, but if it were not existent, it would require giving authority to use the application. In the case that the user may enter data misnomer after verification, the application will show a notice stating that it is wrong of the authenticity of the data. Then it will bring the user back to the login page to enter again correctly or to choose "forget the password."

Figure 5 will explain how the application can help the user to get the forgotten password. As shown in Figure 5, in the event that the employee has forgotten username it, he must restore it through the registered email, which is stored in the customized database for employees. If the e-mail has already existed, the application will send the Password to the user's e-mail. If the e-mail does not exist in the application, the application will give a notice stating that the e-mail is not registered in the database of the application. 


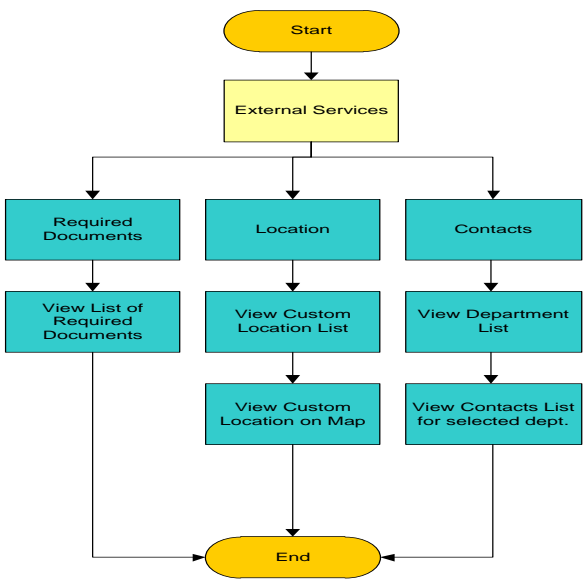

Figure 3. Custom external services

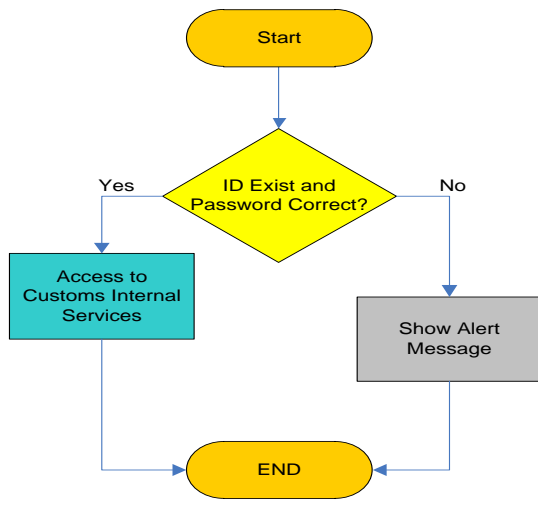

Figure 4. Custom internal login services

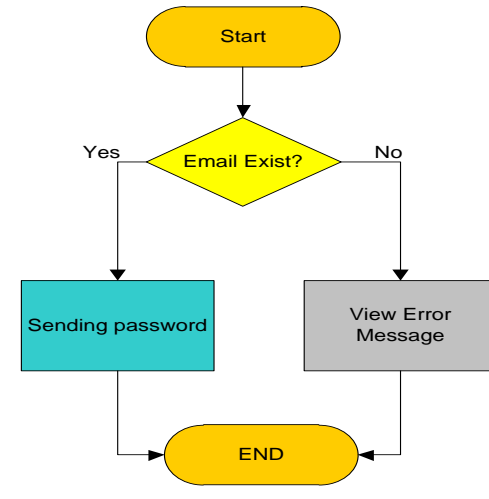

Figure 5. Custom internal forget password

Figure 6 and Figure 7 shows the internal section of the application, it contains five main sections emanated from other sections, and these sections are the registration of companies, reconnaissance suspicion reports, complaints, maintenance requests and Logout option.

a. The company registration: where the employee can query if companies registered in the system, or they are not registered. That by entering the commercial registration number, if the commercial registration number already exists, the company details will be viewed. Moreover, if it does not exist, a notification message will appear stating that the company is not registered.

b. Report suspicion: user can send reconnaissance suspicion reports, and then the employee can view the pending list of the suspicion reports, which is sent by the users, and view the details of the selected record in the list.

c. Complaints: complaints sent to the application by the citizens where it will be worked on its implementation as well as possible, and then stored it in the database of the application.

d. Maintenance and software requests: Internal requests in the application such as maintenance requests for computers, which is directly linked with those in the information technology in the customs department where they are receiving messages and requests from the concerned customs officers and responding to requests for maintenance and information technology. That by filling out the application form entirely with the all required data and sends it to the concerned department. This part characterized by defining two types of employees, the first type is the administrators, and the other type is engineers

e. Logout: To log out of the current account. 


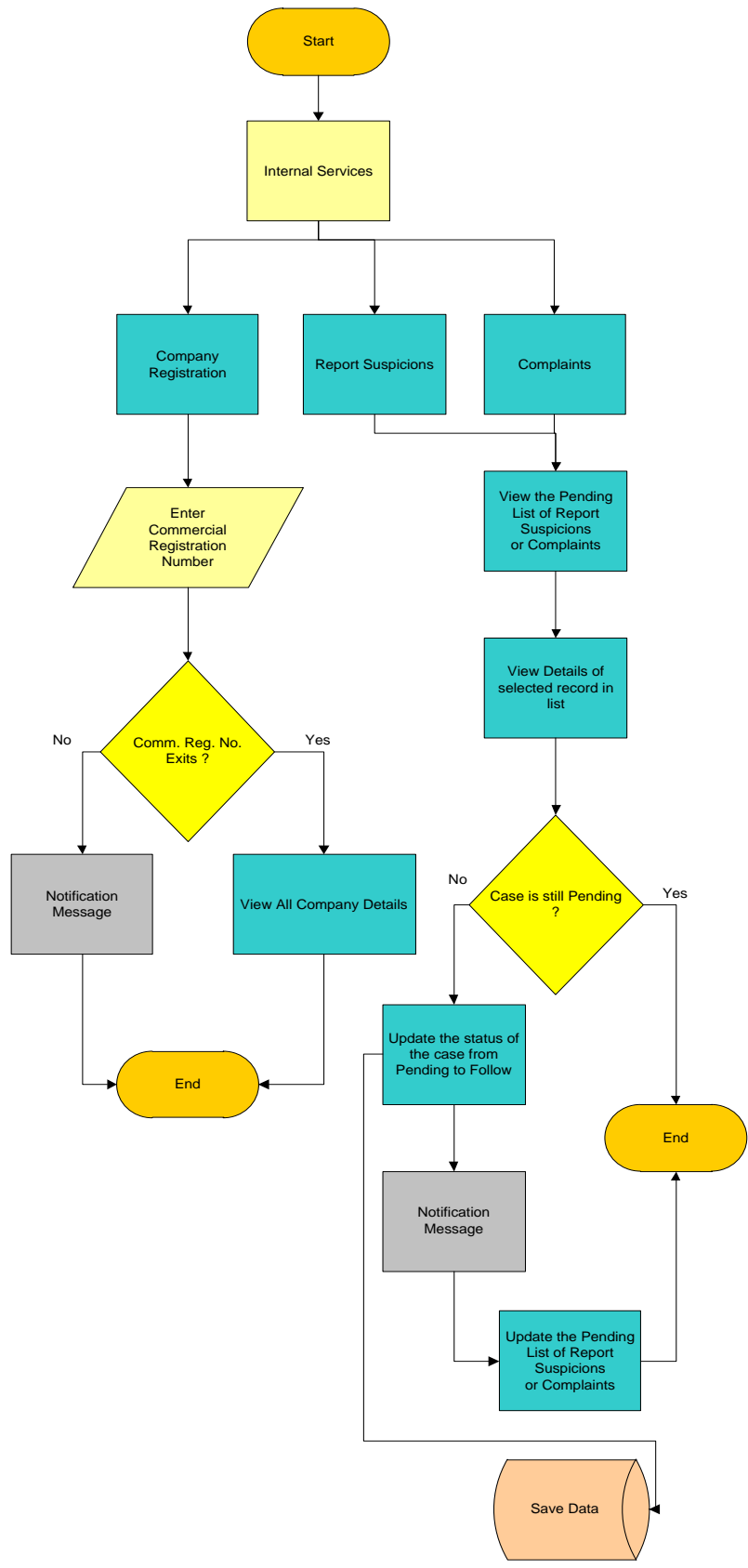

Figure 6. Custom internal services 1

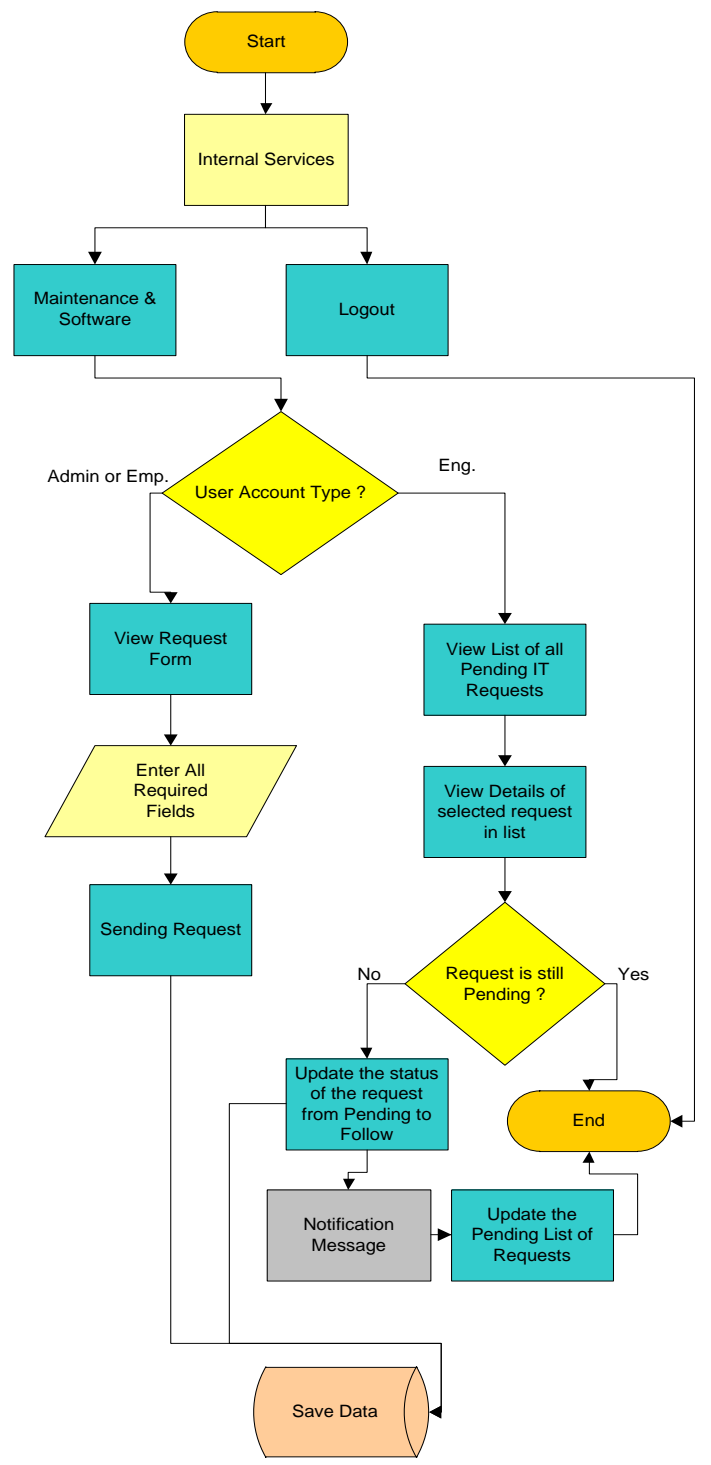

Figure 6. Custom internal services 1

\section{APPLICATION DESIGN}

In this section, the application pages will be displayed to explain the application clearly. Figure 8 shows the home page of the application, which is the login page. The user must have username and password; if the user forgets the password, the user can retake it by e-mail through "forget password?" option. After entering the username and password, the user should click on the login button to be moved to the next page.

Figure 9 shows the main menu of external services and internal services of the application. External services are for citizens, and the internal services are for the employee. Figure 10 shows the external services on the application for the citizen in Kuwait, which the user can choose from the services menu. The external services contain several services like company registration, required documents, reports suspicions, complaints, locations, and contacts.

In addition, this page contains a "back" button to return the user to the previous page (Homepage). As shown in Figure 11, the internal services page provides the employee with five services: The company

Internal and External e-Customs Services IOS Application Case Study: Kuwait Customs... (Soha Aljaber) 
registration, report suspicion, complaints, maintenance and software requests, and the logout option. The user must be an employee in a customs department to choose from this menu.

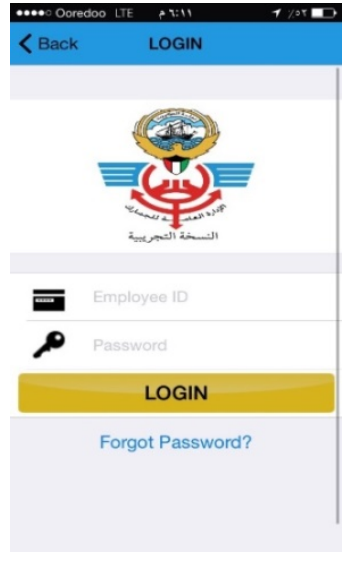

Figure 8. Login page

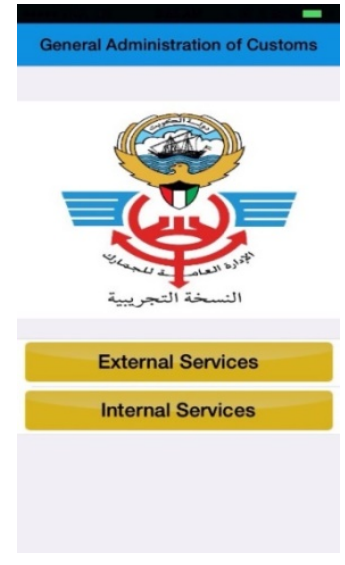

Figure 9. Main menu of application

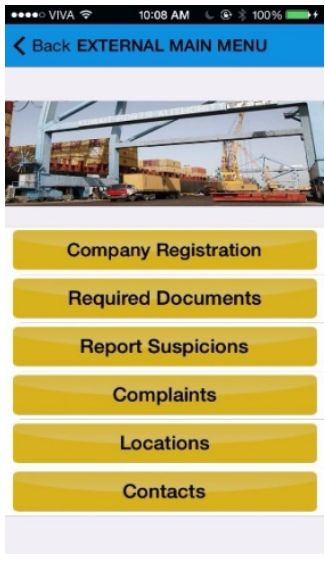

Figure 10. External main menu

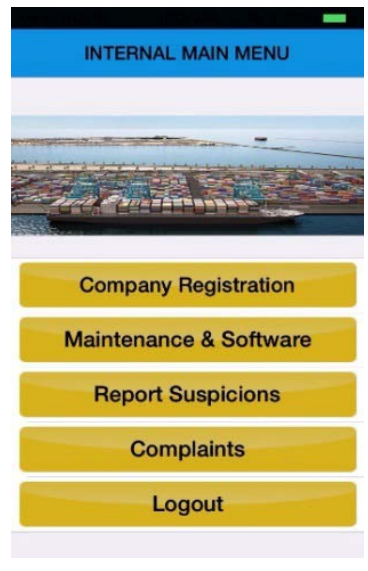

Figure 11. Internal main menu

\section{RESULTS}

After the application has been activated, it found that it was working to solve some of the problems such as requests internal and external requests to the Kuwaiti Customs Department. It saves time and effort in addition to providing money. It must be mentioned that the application lends the character of modernity for the Kuwaiti Customs Department.

a. Goals of the project:

- Improve relations with residents

- $\quad$ Provide services around the clock

- $\quad$ Get rid of bureaucracy between districts

- $\quad$ Reduce the number of auditors to Muscat Municipality

- Provide a one-stop shop to connect to accelerate the execution of transactions Allow the use of electronic services provided by the General Administration of Customs of the population of Kuwait, all of which, whatever the degree of Educational attainment, and anytime, anywhere, through the use of technology best suited to them.

b. Strategies of the project:

Strategies have been determined as follows to ensure the success of the project:

- Configure the appropriate mechanism to provide information outside the municipal buildings and outside working hours.

- The provision of electronic services using different types of technology.

- Enable the general public to pay fees electronically (e-payment). In future Design awareness programs for customs officers and the general public.

- $\quad$ The drafting of new laws and appropriate legislation for e-services in line with it.

- $\quad$ Encourage the public to use electronic services.

This project considers as an e-government project. In order to achieve e-government projects, including the desired goals and to provide high-quality service should provide a number of factors, and the most important of these factors:

i. Availability of appropriate infrastructure: contribute to e-government services in an increased demand for information technology and communications services, which requires the availability of advanced infrastructure able to accommodate this increase in demand without having the quality of the service account. As these services should be accessible to all and enjoy the efficiency and reliability of replay. It is important that this infrastructure be available to all (Universal access) and providing minimum services to all (universal service).

ii. The existence of appropriate regulations and legislation: provide e-government services, new challenges and regulatory and legislative bodies. In addition, it should have the flexibility and the ability to develop regulations and legislation to comply with e-government requirements. 
iii. Revisit the conduct of government transactions method: The application of e-government should not be just an attempt to use modern techniques to automate routine operations and bureaucracy but should be an opportunity to develop the course of these operations and facilitate to fit with the e-government methods.

iv. The provision of adequate privacy and security of information: that the provision of government services on the Internet with the offer of benefits and facilities, but it may allow for attempts to misuse these services. So should adopt appropriate measures to protect these services, including the means, commensurate with their importance and sensitivity commensurate with the requirements of each sector. It is essential to have a balance between Fulfilling information security requirements and flexibility in providing a services Electronic wisdom form that gives confidence to the beneficiary of these services.

v. Capacity-building and human energies: e-government applications need to provide labor is a measure of the skill and the ability to deal with new technologies ably.

Factors that fall under the measure is:

- The citizens, businesses, and government accept e-hold using their services. This factor measures the extent of the application of these services.

- $\quad$ Provide specialized sites on the Internet; this factor will measure how easy it is to use the site.

- $\quad$ Provide specialized center to be able to provide supervision and support for the government-E and assist the co-user group (ordinary citizens and businesses).

- The contribution of the local press in spreading the positive aspects and successes in the use of egovernment, to be done within a comprehensive marketing plan that specifies the required expectations.

- Unify the meaning of the use of the keys to communication devices for all sites, which increases the ease of use of e-government.

- Measure the number of people who use the system to do business with the work of the government and the number of people who use the system for more than what determines the speed and ease of use of the system service.

- Access to the system by foreign nationals to disseminate information about the government abroad. The possibility of citizens and businesses obtain the required information quickly and efficiently

At this section, the most important results achieved by the application of customs will be presented as follows:

- The involvement of citizens in the decision-making process through the discussion forums on the site, which allowed them to participate views and ideas.

- $\quad$ Provide time and effort citizen effort and customs.

- Decreasing the number of customs reviewers, which reflects the citizens take advantage of the site.

- The Customs currently qualifies Clearing offices and Internet cafes in order to rid the transactions Citizens which allows queries for any transaction number and then the possibility of ridding the transaction electronically

- Can any citizen be not even his entrance is available on the Internet or to be non-mm using a computer, be able to redeem his treatment outside the headquarters of the municipality.

- Will extend the service hours of the government working hours to more than where it will have to work clearing evening period offices.

\section{CONCLUSION AND FUTURE WORK}

Arab city is facing major challenges summarized in their ability to cope with the rapid global transformations produced by the information and communication revolution, which began to show new concepts did not pledge to the Arab city before. It is the information revolution to the digital age and the globalization of electronic commerce and e-government and other concepts. Creating an atmosphere of challenge and competition between cities in the region and put it to the test in the face of the winds of change. Arabs either rise to the challenge of their cities and take a privileged position on modern cities of the world map or remain in the pages of history.

What distinguishes the revolution in information and communication about the industrial revolution that changed the features of Western cities is that they are accessible to everyone and not restricted to one. In this large opportunity for Arab cities that have not been able to take advantage of the benefits of the change in the Industrial Revolution, where he became the possibility of cities now has to use information and communication technologies to modernize itself and unambiguous digital dress increases their competitiveness and give dimension to a new through the adoption of projects, "e-government" which means providing public services to citizens through electronic means modern.

This paper sheds light on a sample of an E-government and how it can help to solve many problems. The application provides many services to users and helps to solve many problems of the customs

Internal and External e-Customs Services IOS Application Case Study: Kuwait Customs... (Soha Aljaber) 
administration. The application is divided into two sections; internal services and external services. The internal services section is used by the employee, and the external services section is used by the citizens. The application works on smartphones with IOS systems. Users log in by the civil ID number. It expected to be no expansion in the application and development of future work with the systems of the Gulf Cooperation Council (GCC). There are future projects for the customs administration, and the most important projects are the development of border crossings and the creation of intelligent warehouse.

\section{REFERENCES}

[1] Ahmad Fakhri Alheiajna (2010) E-government project management Arab and international experiences, 1 edn., Hashemite Kingdom of Jordan: Arab Urban Development Institute.

[2] Roadmap for E-Government in The Developing World Pacific Council of International Policy The Western Partner of The Council on Foreign Relations April 2002

[3] Atallah, Sami. "E-government: considerations for Arab States." UNDP (United Nations Development Programme) Sub-regional Resource Facility (2001).

[4] Boujarwah, Abdulazeez S. "E-Government in Kuwait: From Vision to Reality."iiWAS. 2006

[5] Tawfiq bin Mohammed Al-shames (2013) E-government project, 1 edn., Saudi Arabia: King Fahd University of Petroleum and Minerals.

[6] Dr. Ahmad Hamad Al Mohannadi (2011) E-government project Qatar's strategy to build an e-government, 1 edn., Qatar: Government of Qatar.

[7] Ifram Jami (2002) The ICT sector in the Hashemite Kingdom of Jordan, 1 edn., Hashemite Kingdom of Jordan: Ministry of Communications and Information Technology.

[8] Hassan Tawah (2003) E-government experience in Dubai, 1 edn., Oman: Muscat Publisher.

[9] Heilig, L., Voß, S. Information systems in seaports: a categorization and overview (2017) Information Technology and Management, 18 (3), pp. 179-201.

[10] Zaher Al-Sai and Laith Abualigah (2017) 8th International Conference on Information Technology (ICIT), At Jordan - Amman, Volume: Page(s):580 - 587 